\title{
PENGARUH CITRA MEREK, HARGA DAN PROMOSI TERHADAP KEPUTUSAN 45 PEMBELIAN JASA ONLINE GOJEK DI KOTA TANGERANG
}

\author{
Lina Purnama'; ${ }^{1}$ Tri Suyani ${ }^{2}$ dan Nurfitri Eka Hardipamungkas 3 \\ Universitas Pakuan Bogor ${ }^{1}$, Universitas Indraprasta PGRI ${ }^{2,3}$ \\ Lina.purnama2020@yahoo.com ${ }^{1}$; suyanit77@gmail.com² ${ }^{2}$ nehardio3@gmail.com³
}

\begin{abstract}
ABSTRAK
Penelitian ini bertujuan untuk mengetahui pengaruh citra merek, promosi dan harga terhadap keputusan pembelian jasa online gojek di Kota Tangerang. Metode penelitian yang digunakan adalah metode penelitian kualitatif dengan analisis menggunakan uji $\mathrm{t}$, uji $\mathrm{F}$ dan regresi linea berganda. Populasi dalam penelitian ini adalah masyarakat tinggal di Kota Tangerang dengan menggunakan incidental sampling diperoleh sample berjumlah 60. Ada pengaruh dan signifikan citra merek terhadap keputuan pembelian. Semakin dikenal citra merek dengan indikator pembuat merek, merek perusahaan dan merek produk, maka makin tinggi keputusan pembelian jasa online Gojek di Kota Tangerang. Tidak ada pengaruh dan tidak signifikan promosi terhadap keputuan pembelian. Semakin meningkat atau menurun promosi dengan indikator periklanan, promosi penjualan, hubungan masyarakat dan publikasi, tenaga penjualan dan pemasaran langsung, maka tidak akan mempengaruhi keputusan pembelian jasa online Gojek di Kota Tangerang. Ada pengaruh dan signifikan harga terhadap keputuan pembelian. Semakin fleksibel harga dengan indikator affordabiliti, konfirmasi harga dengan produk, harga kompetitif dan kecocokan harga dengan keuntungan, maka makin tinggi keputusan pembelian jasa online Gojek di Kota Tangerang. Variabel harga sangat dominan dibandingkan variabel citra merek dan promosi. Ada pengaruh yang signifikan citra merek, promosi dan harga terhadap keputuan pembelian. Semakin dikenal citra merek dan promosi dengan diskon harga yang kompetitif, maka makin tinggi keputusan pembelian jasa online Gojek di Kota Tangerang.
\end{abstract}

Kata kunci: Brand image, promosi dan harga dan keputusan pembelian

THE INFLUENCE OF BRAND IMAGE, PRICE AND PROMOTION ON THE PURCHASE DECISION OF GOJEK ONLINE SERVICE IN TANGERANG CITY

\section{ABSTRACT}

This study aims to determine the effect of brand image, promotion and price on the purchase decision of Gojek online services in the city of Tangerang. The research method used is a qualitative research method with analysis using test, F test. The population in this study is the people living in the city of Tangerang using incidental sampling obtained a sample of 6o. There is an influence and significant brand image on purchasing decisions. The more known the brand image with indicators of brand makers, corporate brands and product brands, 
the higher the purchase decision of Gojek online services in Tangerang City. No influence and no significant promotion on purchasing decisions. Increasing or decreasing promotion with indicators of advertising, sales promotion, public relations and publications, sales force and direct marketing, it will not affect the purchase decision of Gojek online services in Tangerang. There is no significant influence and price on purchasing decisions The more flexible the price with the affordability indicator, price confirmation with the product, competitive price and match price with profit, the higher the purchase decision of Gojek online services in Tangerang City. The price variable is very dominant compared to the brand image and promotion variables. There is a significant influence of brand image, promotion and price on the purchase decision of Gojek online services. The more well-known brand image and promotion with competitive price discounts, the higher the purchase decision of Gojek online services.

Keywords: Brand image, promotion and price and purchasing decisions

Diterima: 16 Maret 2020; Direvisi: 31 Maret 2020; Diterbitkan: 30 April 2020

\section{PENDAHULUAN}

Pekerjaan sebagai driver gojek online merupakan kesempatan yang luas bagi masyarakat untuk memperoleh penghasilan dalam memenuhi kebutuhan sehari-hari. Gojek online merupakan alternative pekerjaan yang paling mudah prosedur persyaratannnya ditengah persaingan sangat ketat untuk mendapatkan pekerjaan yang sesuai dengan pendidikan sebagai Pegawai Negeri Sipil di Pemerintahan dan sebagai karyawan di perusahaan-perusahaan swasta baik lokal, nasional dan internasional.

Citra merek gojek online telah dikenal luas oleh masyarakat sebagai transportasi go car and go food yang dapat diandalkan dengan harga terjangkau dan aplikasinya mudah digunakan oleh siapapun juga. Gojek online seringkali memberikan promosi biaya transportasi dan biaya pembelian makanan kepada para pelanggan seperti diskon 10, 20, 30, 40 dan 50 persen.

Harga gojek go car and go food tergantung dari jauh dekatnya jarak antara pelanggan dengan tempat yang dituju. Harga gojek bersaing sangat ketat dibandingkan dengan grab online, namun lebih murah apabila dibandingkan dengan taxi blue bird. Pelanggan juga dimanjakan dengan kemudahan dalam sistem pembayaran gojek online dapat berupa tunai atau cash, aplikasi go pay dan ATM.

Beberapa kelemahan gojek online beberapa kali keterlambatan pada waktu penjemputan, harga go car and go food lebih mahal dari pada grab, kesalahpahaman atau miss communication antara driver dengan pelanggan, keterlambatan kedatangan pemesanan go food, apabila merubah arah tujuan dikenakan biaya tambahan, go food kadangkala membayar 1,5 kali dari harga pemesanan, kritik dan saran tidak ditanggapi.

Pendapatan gojek berasal dari pemasangan sponsor perusahaan-perusahaan nasional dan mutlinasional yang memasarkan produk-produknya di aplikasi online Gojek. Pendapatan dana ini dimanfaatkan untuk menarik lebih banyak lagi konsumen menggunakan jasa go car dan go food dengan cara memberikan diskon dan tambahan poin kepada driver gojek.

\section{LANDASAN TEORI}

\section{Citra merek}

Menurut Ferrinadewi, Erna, (2008)

bahwa dimensi citra merek terdiri dari 
47ndicator pembuat merek, merek perusahaan dan merek produk.

Menurut Aeker, Arnold, davis, Drezmer, Hogan, Keller, Mowen and Minor, Plummer, Upshaw, Brexendorf and Kernstock, Wijaya, (2012) dengan judul Dimention of Brand image Image: A Conceptual Review from the Perspective of Brand image Communication. 2013. Bambang Sukma Wijaya. European Journal of Business and Management Vol 5 No. 31, 2013. ISSN 222-2839. DOI 10.13140/ejbm.2013.55.65 bahwa citra citra merek terdiri dari: identitas citra merek (Brand image Identity), personal citra merek (Brand image Personalty), asosiasi citra merek (Brand image Association), sikap dan perilaku citra merek (Brand image Behavior and Attitude), dan keuntungan dan kompetensi citra merek (Brand image Competence and Benefit).

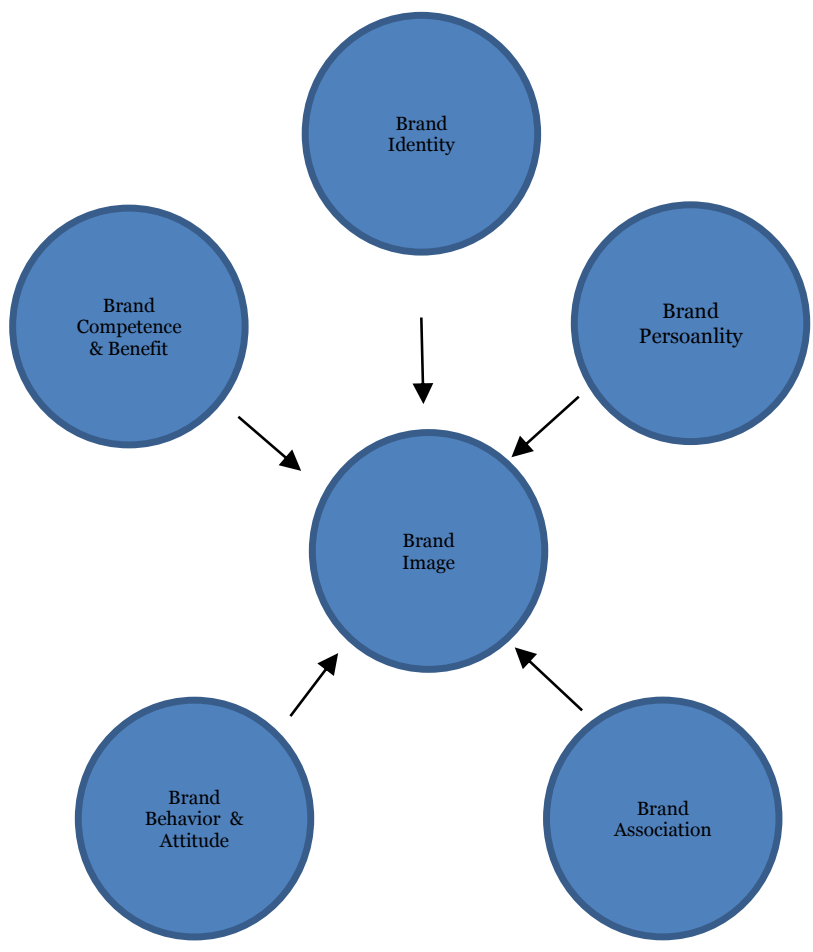

Gambar 1. Dimensi Brand Image

\section{Harga}

Stanton, William (2003). Indikator harga terdiri dari: affordabiliti, konfirmasi harga dengan produk, harga kompetitif dan kecocokan harga dengan keuntungan.

Menurut Herman Simonn, (2017). Pricing and the CEO. Marketing Journal. https://www.marketingjournal.org/pricingand-the-ceo-hermann-simon-chairman-simonkucher-partners/Nilai superior adalah suatu keharusan: Penentuan harga premium hanya berlaku jika suatu perusahaan menawarkan nilai superior kepada pelanggan.

1. Hubungan harga-nilai adalah keunggulan kompetitif yang menentukan. Produk premium yang sukses mendapatkan keunggulan kompetitif citra mereka yang sebenarnya dari nilai tinggi citra mereka (secara objektif, absolut), diterjemahkan ke dalam hubungan harga-nilai yang sesuai.

2. Inovasi adalah fondasinya: secara umum, inovasi memberikan fondasi bagi posisi harga premium yang sukses dan berkelanjutan. Ini berlaku untuk inovasi terobosan serta perbaikan terus-menerus, seperti Miele di bawah moto "Untuk selamanya Lebih Baik".

3. Konsisten, kualitas tinggi adalah suatu keharusan. Prasyarat ini muncul berkalikali: pemasok premium yang sukses mempertahankan tingkat kualitas yang tinggi dan sangat konsisten. Layanan citra mereka juga harus memenuhi persyaratan yang sama.

4. Pricer premium memiliki citra merek yang kuat: salah satu fungsi dari citra merek yang kuat ini adalah untuk mengubah keunggulan teknologi - yang seringkali bersifat sementara - menjadi keunggulan citra yang tahan lama.

5. Penentu harga premium banyak berinvestasi dalam komunikasi: Citra mereka tahu bahwa citra mereka harus membuat nilai dan keunggulan produk citra mereka dapat dipahami dan dipahami oleh konsumen. Ingat: hanya nilai yang dianggap yang diperhitungkan.

6. Pricer premium menghindar dari penawaran khusus: Citra mereka ragu untuk menawarkan promosi dan penawaran khusus. Jika promosi yang citra mereka tawarkan terlalu sering atau terlalu curam, instrumen ini dapat membahayakan posisi 
harga

premium

Menurut Harry Macdivitt, (2012). Value-Based Price: Drive Sales and Boost Your Bottom Line by Craeting, Communicating and Capturing Customer Value. E-ISBN 978-0-07176860-3. New York: McGraw-Hill Company. penetapan harga berbasis nilai: tingkatkan penjualan, tingkatkan keuntungan anda dengan menciptakan, mengkomunikasikan, dan menangkap nilai pelanggan

\section{Promosi}

Menurut Phillip Kotler, (2015) Marketing Management. $15^{\text {th }}$ Edition. Dimensi promosi antara lain periklanan, promosi penjualan, hubungan masyarakat dan publikasi, tenaga penjualan dan pemasaran langsung.

\section{Keputusan Pembelian}

Menurut Phillip Kotler, (2015) Marketing Management. $15^{\text {th }}$ Edition. Dimensi keputusan pembelian terdiri dari: pengenalan masalah, pencarian informasi dan alternative evaluasi.

\section{Kerangka Pemikiran}

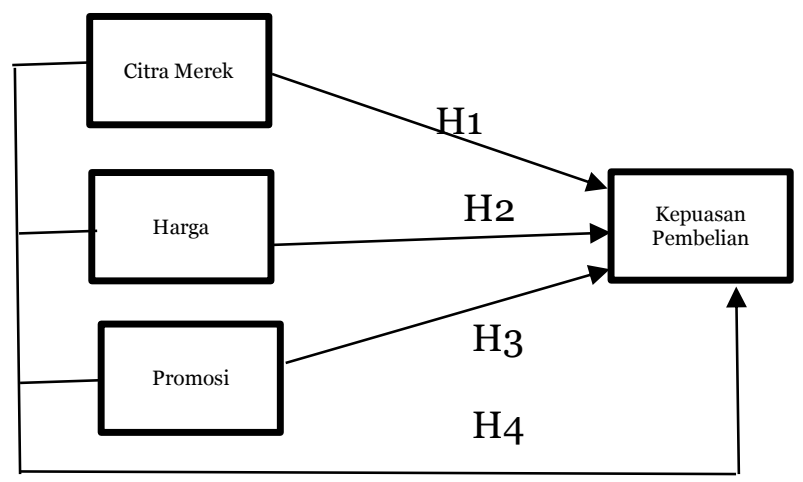

Gambar 1. Kerangka Penelitian

\section{Hipotesis}

H1: Ada pengaruh citra merek terhadap keputusan pembelian jasa online Gojek di Kota Tangerang;
H2: Ada pengaruh promosi terhadap keputusan pembelian jasa online Gojek di Kota Tangerang;

H3: Ada pengaruh harga terhadap keputusan pembelian jasa online Gojek di Kota Tangerang;

$\mathrm{H}_{4}$ : Ada pengaruh citra merek, promosi dan harga terhadap keputusan pembelian jasa online Gojek di Kota Tangerang;

\section{METODE PENELITIAN}

Metode penelitian yang digunakan adalah metode penelitian kualitatif dengan analisis menggunakan uji $\mathrm{t}$, uji $\mathrm{F}$ dan regresi linea berganda. Populasi dalam penelitian ini adalah masyarakat tinggal di Kota Tangerang dengan menggunakan incidental sampling diperoleh sample berjumlah 70 .

\section{HASIL DAN PEMBAHASAN}

Berdasarkan uji validitas, reliabilitas dan normalitas dengan menggunakan software SPSS diperoleh nilai validitas dan Cronbach alpha lebih besar dari o,6o maka dinyatakan valid dan reliabel. Uji normalitas dengan menggunakan Kolmogorov Smirnov diperoleh data berdistribusi normal..

Berdasarkan uji model structural $t$ values and $\mathrm{P}$ values dengan software SPSS menunjukkan hasil sebagai berikut: Hipotesis pertama $t$ hitung $(3,048) \geq t$ tabel $(2,00)$ dengan signifikansi hitung $(0,003) \leq 0,05$, dapat diartikan ada pengaruh dan signifikan citra merek terhadap keputuan pembelian; Hipotesis kedua $t$ hitung $(1,278) \leq$ dari t tabel $(2,00)$ dengan signifikansi hitung $(0,206) \geq$ o,05, dapat diartikan tidak ada pengaruh dan tidak signifikan promosi terhadap keputuan pembelian; Hipotesis ketiga t hitung $(17,023) \geq$ dari t tabel $(2,00)$ dengan signifikansi hitung $(0,00) \leq 0,05$, dapat diartikan ada pengaruh dan signifikan harga terhadap keputuan pembelian; 
Tabel 1. Uji t

\begin{tabular}{|c|c|c|c|c|c|c|}
\hline \multicolumn{7}{|c|}{ Coefficients $^{\mathrm{a}}$} \\
\hline \multirow[b]{2}{*}{ Mode } & & \multicolumn{2}{|c|}{ Unstandardized Coefficients } & \multirow{2}{*}{$\begin{array}{c}\text { Standardized } \\
\text { Coefficients } \\
\text { Beta }\end{array}$} & \multirow[b]{2}{*}{$t$} & \multirow[b]{2}{*}{ Sig. } \\
\hline & & B & Std. Error & & & \\
\hline \multirow[t]{4}{*}{1} & (Constant) & .166 &, 502 & & .330 & .742 \\
\hline & Citra Merek & 124 & .041 & 136 & 3,048 & .003 \\
\hline & Promosi & .060 & ,047 & ,058 & 1,278 & ,206 \\
\hline & Harga & 812 & .048 & 838 & 17,023 &, 000 \\
\hline
\end{tabular}

Hipotesis keempat F hitung $(256,157) \geq$ dari $\mathrm{F}$ tabel $(4,13)$ dengan signifikansi hitung $(0,00) \leq 0,05$, dapat diartikan ada pengaruh yang signifikan citra merek, promosi dan harga terhadap keputuan pembelian.

Tabel 2. Uji F

ANOVA $^{\mathrm{a}}$

\begin{tabular}{|rl|r|r|r|r|c|}
\hline Model & & \multicolumn{1}{|c|}{$\begin{array}{c}\text { Sum of } \\
\text { Squares }\end{array}$} & \multicolumn{1}{c|}{ df } & Mean Square & F & Sig. \\
\hline 1 & Regression & 99,383 & 3 & 33,128 & 256,157 &, $000^{\mathrm{b}}$ \\
& Residual & 7,372 & 57 &, 129 & & \\
& Total & 106,754 & 60 & & & \\
\hline
\end{tabular}

a. Dependent Variable: Keputusan Pembelian

b. Predictors: (Constant), Harga, Citra Merek, Promosi

Berdasarkan $\mathrm{R}$ square dengan menggunakan software SPSS diperoleh hasil o.931 artinya variabel citra merek dan variabel promosi mempengaruhi keputusan pembelian batik Karawang di Ramayana Mall, Karawang sejumlah 93,1\% dan 6,9\% dipengaruhi oleh variabel lainnya.

Tabel R Square

Model Summary
\begin{tabular}{|l|l|r|r|r|}
\hline Model & R & R Square & $\begin{array}{c}\text { Adjusted R } \\
\text { Square }\end{array}$ & $\begin{array}{c}\text { Std. Error of } \\
\text { the Estimate }\end{array}$ \\
\hline 1 &, $965^{\text {a }}$ &, 931 &, 927 &, 360 \\
\hline
\end{tabular}

a. Predictors: (Constant), Harga, Citra Merek, Promosi

\section{Pembahasan}

\section{Citra Merek terhadap Keputusan Pembelian}

Hipotesi Ho diterima karena $\mathrm{t}$ hitung $(3,048) \geq t$ tabel $(2,00)$ dengan signifikansi hitung $(0,003) \leq 0,05$, dapat diartikan ada pengaruh dan signifikan citra merek terhadap keputuan pembelian. Semakin dikenal citra merek dengan indikator pembuat merek, merek perusahaan dan merek produk, maka makin tinggi keputusan pembelian jasa online Gojek di Kota Tangerang. Penelitian ini mendukung penelitian sebelumnya yang dilakukan oleh Hafish Novansa dan Hapsi Ali, (2014) dengan judul Purchase Decision Model: Analysis of Brand Image, Brand Awereness and Price (Case Study: SMESCO Indonesia SME Products) yang mengatakan ada pengaruh citra merek terhadap keputusan pembelian.

\section{Promosi terhadap Keputusan Pembelian}

Hipotesis H1 diterima karena t hitung $(1,278) \leq$ dari t tabel $(2,00)$ dengan signifikansi hitung $(0,206) \geq 0,05$, dapat diartikan tidak ada pengaruh dan tidak signifikan promosi terhadap keputuan pembelian. Promosi dengan indikator periklanan, promosi penjualan, hubungan masyarakat dan publikasi, tenaga penjualan dan pemasaran langsung semakin meningkat atau semakin menurun, maka tidak akan mempengaruhi keputusan pembelian jasa online Gojek di Kota Tangerang

Penelitian ini juga bertolak-belakang penelitian sebelumnya yang dilakukan oleh Erna S. Imaningsih dan Saiful Rahman, (2018) dengan judul The Model of Product Quality, Promotion, Price and Purchase Decisions yang menyatakan ada pengaruh promosi terhadap keputusan pembelian.

\section{Harga terhadap Keputusan Pembelian}

Hipotesis H1 diterima karena t hitung $(17,023) \geq$ dari t tabel $(2,00)$ dengan signifikansi hitung $(0,00) \leq 0,05$, dapat diartikan ada pengaruh yang signifikan harga terhadap keputusan pembelian. Semakin fleksibel harga dengan indikator affordabiliti, konfirmasi harga dengan produk, harga kompetitif dan kecocokan 
harga dengan keuntungan, maka makin tinggi keputusan pembelian jasa online Gojek di Kota Tangerang

Penelitian ini mendukung penelitian sebelumnya yang dilakukan oleh Hafish Novansa dan Hapsi Ali, (2014) dengan judul Purchase Decision Model: Analysis of Brand Image, Brand Awereness and Price (Case Study: SMESCO Indonesia SME Products) yang mengatakan ada pengaruh harga terhadap keputusan pembelian.

Penelitian ini juga mendukung penelitian sebelumnya yang dilakukan oleh Erna S. Imaningsih dan Saiful Rahman, (2018) dengan judul The Model of Product Quality, Promotion, Price and Purchase Decisions yang menyatakan ada pengaruh harga terhadap keputusan pembelian.

\section{Citra Merek, Promosi dan Harga terhadap Keputusan Pembelian}

Hipotesis $\mathrm{H} 1$ diterima karena $\mathrm{F}$ hitung $(256,157) \geq$ dari $t$ tabel $(2,00)$ dengan signifikansi hitung $(0,00) \leq 0,05$, dapat diartikan ada pengaruh yang signifikan citra citra merek, promosi dan harga terhadap keputusan pembelian. Semakin dikenal citra merek, promosi yang seringkali dilakukan dengan diskon harga, maka semakin banyak masyarakat yang memutuskan untuk menggunakan jasa online Gojek di Kota Tangerang

Penelitian ini mendukung penelitian sebelumnya yang dilakukan oleh Moch Syeha Sakti Alif, (2014) dengan judul pengaruh citra merek, harga dan promosi terhadap keputusan pembelian laptop merek HP (Studi pada Hi Tech Mall Surabaya). yang mengatakan ada pengaruh citra merek, promosi dan harga terhadap keputusan pembelian.

\section{KESIMPULAN DAN SARAN}

\section{Kesimpulan}

Kesimpulan dalam penilitian ini adalah sebagai berikut:

1. Ada pengaruh dan signifikan citra merek terhadap keputuan pembelian. Semakin dikenal citra merek dengan indikator pembuat merek, merek perusahaan dan merek produk, maka makin tinggi keputusan pembelian jasa online Gojek di Kota Tangerang;

2. Tidak ada pengaruh dan tidak signifikan promosi terhadap keputuan pembelian. Semakin meningkat atau menurun promosi dengan indikator periklanan, promosi penjualan, hubungan masyarakat dan publikasi, tenaga penjualan dan pemasaran langsung, maka tidak akan mempengaruhi keputusan pembelian jasa online Gojek di Kota Tangerang

3. Ada pengaruh dan signifikan harga terhadap keputuan pembelian. Semakin fleksibel harga dengan indikator affordabiliti, konfirmasi harga dengan produk, harga kompetitif dan kecocokan harga dengan keuntungan, maka makin tinggi keputusan pembelian jasa online Gojek di Kota Tangerang. Variabel harga sangat dominan dibandingkan variabel citra merek dan promosi;

4. Ada pengaruh yang signifikan citra merek, promosi dan harga terhadap keputuan pembelian. Semakin dikenal citra merek dan promosi dengan diskon harga yang kompetitif, maka makin tinggi keputusan pembelian jasa online Gojek di Kota Tangerang.

\section{Saran}


1. Disarankan kepada driver jasa online gojek agar menjaga citra citra merek gojak sehingga diharapkan semakin banyak masyarakat yang menggunakan jasa Gojek;

2. Disarankan kepada peemilik peusahaan agar sering melakukan promosi harga diskon agar semakin banyak masyarakat yang menggunakan jasa online Gojek.

\section{Daftar Pustaka}

Aeker, Arnold, davis, Drezmer, Hogan, Kell;er, Mowen and Minor, Plummer, Upshaw, Brexendorf and Kernstock, Wijaya, (2012). Brand Image: A Conceptual Review from the Perspective of Brand image Communication. 2013. Bambang Sukma Wijaya. European Journal of Business and Management Vol 5 No. 31, 2013. ISSN 222-2839. DOI 10.13140/ejbm.2013.55.65.

Erna S. Imaningsih dan Saiful Rahman, (2018) dengan judul The Model of Product Quality, Promotion, Price and Purchase Decisions. Jakarta: Jurnal Ekonomi Volume XXIII, No. 02, Juli 2018. 260271.

Ferrinadewi, Erna, (2008). Brand and Consumer Psychology: Implication on Marketing Strategies. First Edition. Yogyakarta: Graha Ilmu.

Hafish Novansa dan Hapsi Ali, (2014). Purchase Decision Model: Analysis of Brand Image, Brand Awereness and Price (Case Study: SMESCO Indonesia SME Products). Scholarsmepub.com

Harry Macdivitt, (2012). Value-Based Price: Drive Sales and Boost Your Bottom Line by Craeting, Communicating and Capturing Customer Value. E-ISBN 978o-o7-176860-3. New York: McGraw-Hill Company.

https://www.amazon.com/Value-

Based-Pricing-Creating-

Communicating-

Capturing/dp/oo71761683/ref=pd_sbs

-14_5/144-0153140-

2730677?_encoding $=U T F 8 \& p d \_r d \_i=O$ o71761683\&pd_rd_r=1ba11b65-979f-

$4 e f f-b 9 d b-$

$3 c 89 d 76 f b c o c \& p d \_r d \_w=q Y x J 8 \& p d \_r d$

$\_w g=S L d Z l \& p f \_r d \_p=12 b 8 d 3 e 2-e 203^{-}$

4b23-a8bc-

68a7d2806477\&pf_rd_r=WSVQoT6J85

$1 C F 44 Y M W J P \& p s c=1 \&$ refRID $=W S V Q o$

T6J851CF44YMWJP.

Herman Simonn, (2016). Pricing and the CEO. Marketing Journal. https://www.marketingjournal.org/pri cing-and-the-ceo-hermann-simonchairman-simon-kucher-partners/

Moch Syeha Sakti Alif, (2014). Pengaruh Citra Merek, Harga dan Promosi terhadap Keputusan Pembelian Laptop Merek HP (Studi pada Hi Tech Mall Surabaya).

Stanton, William (2003). Principles of Marketing. Interpretation by Sadu Sandudu. Volume One, Tenth Edition. Erland.

Phillip Kotler, (2015) Marketing Management. $15^{\text {th }}$ Edition. New York: Pearson. 